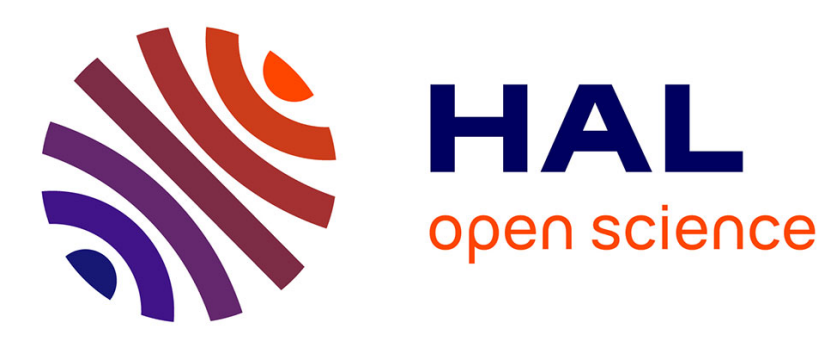

\title{
Fatigue Damage Initiation of a PA66/Glass Fibers Composite Material
}

B Esmaeillou, P Fereirra, V Bellenger, A Tcharkhtchi

\section{To cite this version:}

B Esmaeillou, P Fereirra, V Bellenger, A Tcharkhtchi. Fatigue Damage Initiation of a PA66/Glass Fibers Composite Material. Journal of Applied Polymer Science, 2012, 125, pp.4007-4014. 10.1002/app.36728 . hal-01202706

\section{HAL Id: hal-01202706 https://hal.science/hal-01202706}

Submitted on 21 Sep 2015

HAL is a multi-disciplinary open access archive for the deposit and dissemination of scientific research documents, whether they are published or not. The documents may come from teaching and research institutions in France or abroad, or from public or private research centers.
L'archive ouverte pluridisciplinaire HAL, est destinée au dépôt et à la diffusion de documents scientifiques de niveau recherche, publiés ou non, émanant des établissements d'enseignement et de recherche français ou étrangers, des laboratoires publics ou privés. 


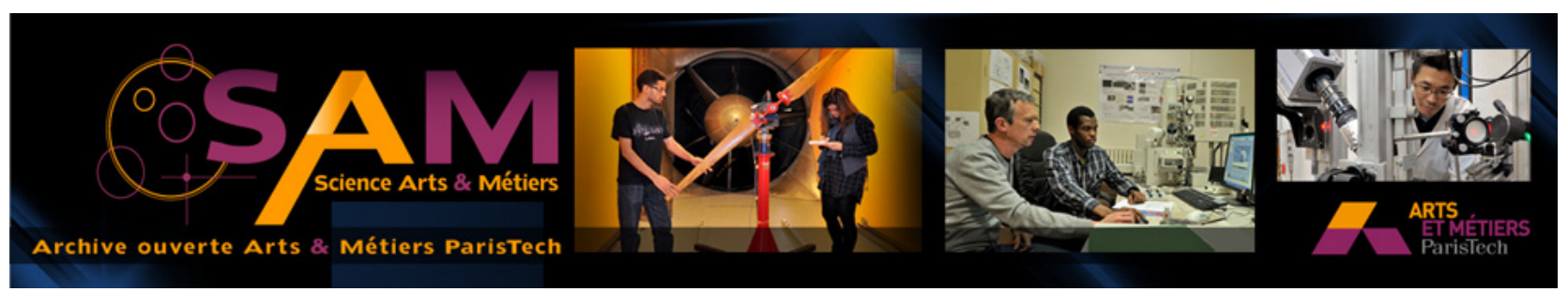

Science Arts \& Métiers (SAM)

is an open access repository that collects the work of Arts et Métiers ParisTech researchers and makes it freely available over the web where possible.

This is an author-deposited version published in: http://sam.ensam.eu

Handle ID: .http://hdl.handle.net/10985/10083

\section{To cite this version :}

B ESMAEILLOU, P FEREIRRA, V BELLENGER, A TCHARKHTCHI - Fatigue Damage Initiation of a PA66/Glass Fibers Composite Material - Journal of Applied Polymer Science - Vol. 125, p.4007-4014. - 2012 


\title{
Fatigue Damage Initiation of a PA66/Glass Fibers Composite Material
}

\author{
B. Esmaeillou, P. Fereirra, V. Bellenger, A. Tcharkhtchi \\ PIMM, Arts and Métiers ParisTech, 151, Boulevard de l'Hôpital, 75013 Paris, France
}

\begin{abstract}
Fatigue damage initiation of a PA66/glass fiber composite material is studied with interrupted tests carried out with an "alternative bending device" and a small applied strain. During the damage initiation period, no change of macroscopic properties, density, cristallinity ratio, glass transition temperature, and flexural elastic modulus is observed. Polysequential tests are carried out with three rest times differing by their length. These rest times allow the relaxation of macromolecular chains in the region of the microdefects and increase the number
\end{abstract}

\section{INTRODUCTION}

The fatigue behavior of composite materials with short fibers is still a key problem despite the progress in material science. For many molded parts, the lifetime prediction is crucial. In the automotive industry, pressures and temperatures in engines are inclined to go up, which makes the fatigue properties of these parts critical. A fatigue curve displays the variation of the induced stress versus the number of cycles for a given strain and frequency. Generally, these curves display three parts: (1) a fast decay of the induced stress due to the setting up of a thermal regime: an increasing temperature involves a decreasing elastic modulus; (2) a long plateau (period 2) during which the induced stress decreases only slightly without any significant temperature change; (3) a sudden stress reduction corresponding to the coalescence of microdefects followed by the sample fracture. For PA66/glass fibers, several research works ${ }^{1-3}$ report that microcavitation (crack) is initiated by the build-up of microdefects at fiber ends. Damage initiation occurs during the period 2 of stress stabilization. For unnotched samples of amorphous polymers, no significant change in macroscopic properties ${ }^{4}$ (macroscopic compliance, cristallinity ratio, and transition temperatures) is observed during this period. The aim of this work is

Correspondence to: V. Bellenger (vbellenger@gmail.com). of cycles at fracture. The most efficient stop is the one just before the final fracture. The comparison of the fatigue behavior of the composite and its neat matrix shows that the microdefects relaxed during the break are identical to those which initiate damage and final fracture. (C) 2012 Wiley Periodicals, Inc. J Appl Polym Sci 125: 4007-4014, 2012

Keywords: polyamide 66; composites; damage zone; fatigue tests; relaxation

to study damage initiation by the way of interrupted fatigue tests and polysequential fatigue tests. Interrupted fatigue tests are carried out and, during every rest time, dogbone samples are analyzed by differential scanning calorimetry (melting temperature $T_{m}$, cristallinity ratio $x_{c}$ ), density measurements, and mechanical testing (dynamic mechanical analysis, flexural modulus, and ultimate stress). With polysequential fatigue tests, the effect of the rest time and stop location on the fatigue lifetime is investigated.

\section{MATERIALS AND METHODS}

The composite material is a thermoplastic polyamide 66 matrix reinforced by short glass fibres. The fiber content was measured by gravimetry on six samples after a 3-h pyrolysis at $500^{\circ} \mathrm{C}$. It is equal to $30.7 \pm$ 0.05 . The length is $203 \pm 12 \mu \mathrm{m}$, and the diameter $30 \pm 1 \mu \mathrm{m}$. The fraction crystallinity $x_{c}$ is determined by DSC experiments using the ratio $\frac{\Delta H_{m}}{\Delta H_{m}^{c}}$, where $\Delta H_{m}$ is the experimental value of melting enthalpy and $\Delta H_{m}^{c}$ the melting enthalpy of the $100 \%$ crystalline polymer. $\Delta H_{m}^{c}=192 \mathrm{~J} / \mathrm{g} .{ }^{5}$ Dogbone specimens, $150 \times 20 \times 4 \mathrm{~mm}$, were injected with an injectionmolding machine (DK Codim $175 \mathrm{~T}$ ) according to the AFNOR NF T 51-034 standard.

The most constrained part of the sample during the fatigue test was determined by a linear elastic calculation, $x_{\max }$. It is located at a distance of $18 \mathrm{~mm}$ from the embedded part ${ }^{6}$ (Fig. 1). Sample surface is observed in this most constrained part by optical microscopy with an Olympus $\mathrm{BH} 2$ or by scanning 


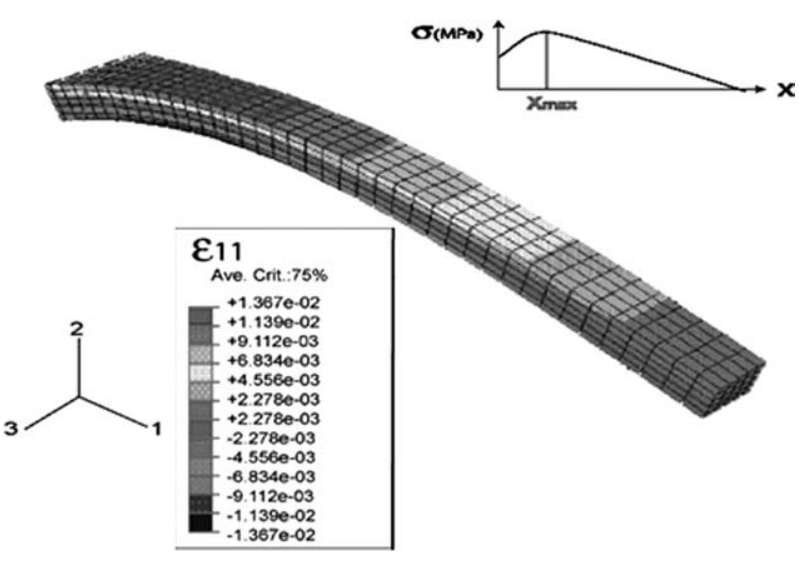

Figure 1 Most constrained area of a dogbone sample indicated by a linear elastic calculation. ${ }^{6}$

electron microscopy with a Hitachi S-4800 apparatus at an accelerating potential of $0.8 \mathrm{kV}$. Samples are not metallized, because a morphological analysis does not require this surface treatment. A specimen section perpendicular to the injection direction observed by optical microscopy indicates that most fibers are oriented in the injection direction. The loss modulus $E^{\prime \prime}$ is measured by viscoelasticimetry on a NETZSCH DMA 242 apparatus. The test is performed in three-point bending mode at a $10 \mathrm{~Hz}$ frequency, with a static force of $4 \mathrm{~N}$ and a dynamic force of $2 \mathrm{~N}$. The heating rate is $5^{\circ} \mathrm{C} / \mathrm{min}$. The initial mechanical properties are determined at $23^{\circ} \mathrm{C}$ and $50 \%$ HR in bending mode with an INSTRON 4502. The strain rate is $2 \mathrm{~mm} / \mathrm{min}$, and the bending length is $60 \mathrm{~mm}$. The elastic modulus $E$ and the ultimate stress $\sigma_{u}$ are calculated with the following relationships, where $D$ is the bending length, $h$ the sample thickness, $b$ the sample width, $F / \gamma$ the initial slope of the stress-strain curve, and $F_{\max }$ the maximum value of the load.

$$
E=\left(\frac{D^{2}}{4 \cdot h \cdot b^{3}}\right)\left(\frac{F}{\gamma}\right) \quad \sigma_{u}=\frac{3 F_{\max } D}{2 b h^{2}}
$$

The fatigue test ${ }^{1}$ is performed in a flexural alternate bending device (Fig. 2), at a frequency of $10 \mathrm{~Hz}$ with an $R=\frac{\varepsilon_{\min }}{\varepsilon_{\max }}$ value equal to -1 at $23^{\circ} \mathrm{C}$ and $50 \%$ $\mathrm{RH}$. During the fatigue test, a decreasing amplitude of the induced stress is observed, but the ratio $\frac{\sigma_{\min }}{\sigma_{\max }}$ does not change. The curves $\sigma_{\min }=f$ (number of cycles) and $\sigma_{\max }=f$ (number of cycles) are symmet-

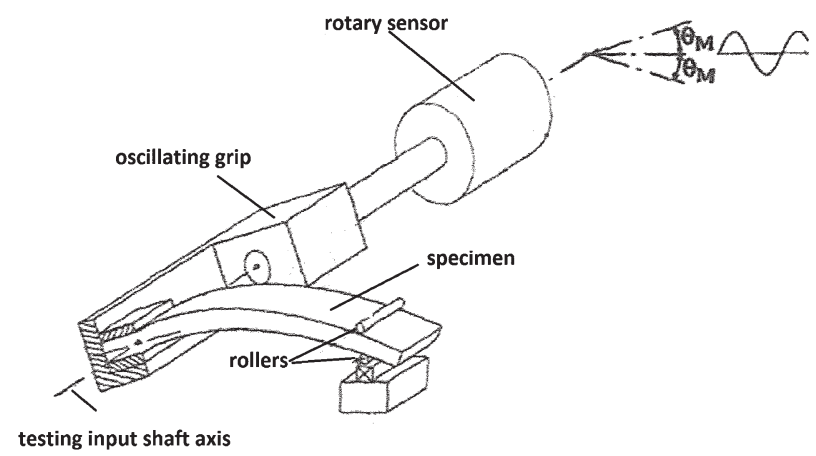

Figure 2 Alternative bending device used for fatigue tests. ${ }^{6}$

rical. The applied amplitude strain is 0.013 for interrupted fatigue tests and 0.017 for polysequential fatigue tests. For these last tests, the first break occurs at 30,000 loading cycles, and the rest time varies between 2 and $30 \mathrm{~min}$. Then, the same approach is done for a stop at 45,000 loading cycles and for a stop at 60,000 loading cycles close to the final sample fracture. For some polysequential fatigue tests, surface sample is polished in the most constrained part before optical microscopy observation at the rest time. After observation, the fatigue strain is again applied on the same sample. The time of break is at most $10 \mathrm{~min}$. The surface temperature in the most constrained area is measured during the test by a RAYTEK infrared camcorder.

\section{RESULTS AND DISCUSSION}

Interrupted fatigue tests are performed at $10 \mathrm{~Hz}$ with an applied amplitude strain of 0.013. The physicochemical and mechanical properties, density, critallinity ratio, loss modulus, flexural modulus, and ultimate stress are measured after 300,000 and 500,000 loading cycles. The values reported in Table I show that these properties are not modified during the damage initiation period. It does not mean that there is no defect build-up, but their size/concentration is too small [Fig. 3(a)], to induce a variation of the macroscopic properties. Before 500,000 cycles, the size of submicron defects in the most constrained area is smaller than $0.2 \mu \mathrm{m}$. The mean value of the ultimate stress seems to increase with the number of loading cycles, but it is not significant, taking into account the standard deviations. The loss

TABLE I

Physicochemical and Mechanical Properties of PA66/GF Versus Number of Loading Cycles

\begin{tabular}{lccccc}
\hline & Density $\left(\mathrm{kg} / \mathrm{m}^{3}\right)$ & $x_{c}(\%)$ & $E^{\prime \prime}{ }_{42}{ }^{\circ} \mathrm{C}(\mathrm{MPa})$ & $E(\mathrm{MPa})$ & $\sigma_{u}(\mathrm{MPa})$ \\
\hline 0 cycle loading & $1409 \pm 13$ & $35 \pm 4$ & 343 & $6680 \pm 200$ & $190 \pm 7$ \\
300,000 cycle loading & $1374 \pm 22$ & $36 \pm 3$ & 340 & $6860 \pm 70$ & $193 \pm 8$ \\
500,000 cycle loading & $1404 \pm 8$ & $38 \pm 5$ & 290 & $6148 \pm 612$ & $204 \pm 19$ \\
\hline
\end{tabular}



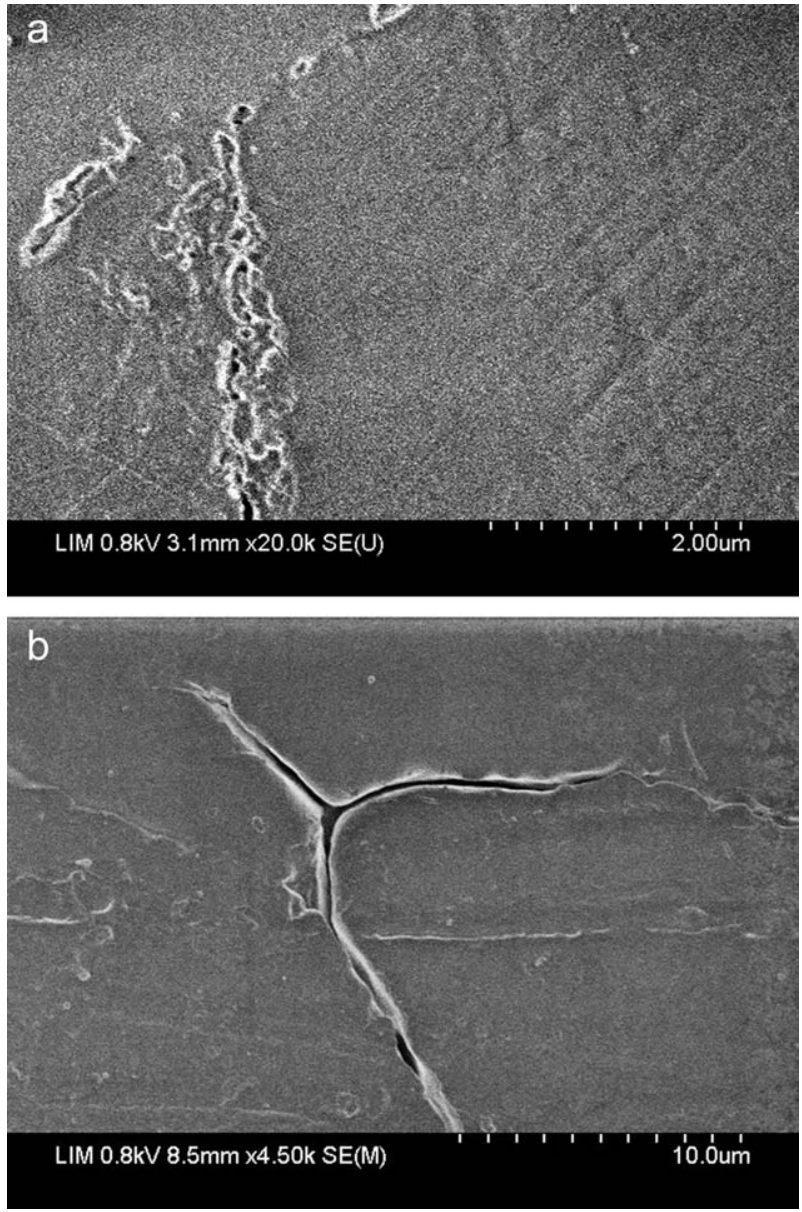

Figure 3 SEM observation of the most constrained area of a specimen tested at $10 \mathrm{~Hz}$ and $\varepsilon=0.013$ (interrupted test), (a) after 300,000 loading cycles and (b) after 500,000 loading cycles.

modulus $E^{\prime \prime}$ measured at $42^{\circ} \mathrm{C}$ (the maximum value corresponding to $T_{\alpha}$ is $55^{\circ} \mathrm{C}$ ) seems to be constant except near the fracture $(500,000$ cycles), where it decreases when microdefects are generated [Fig. 3(b)]. Between 0 and 500,000 cycles, flexural properties are unchanged taking into account the

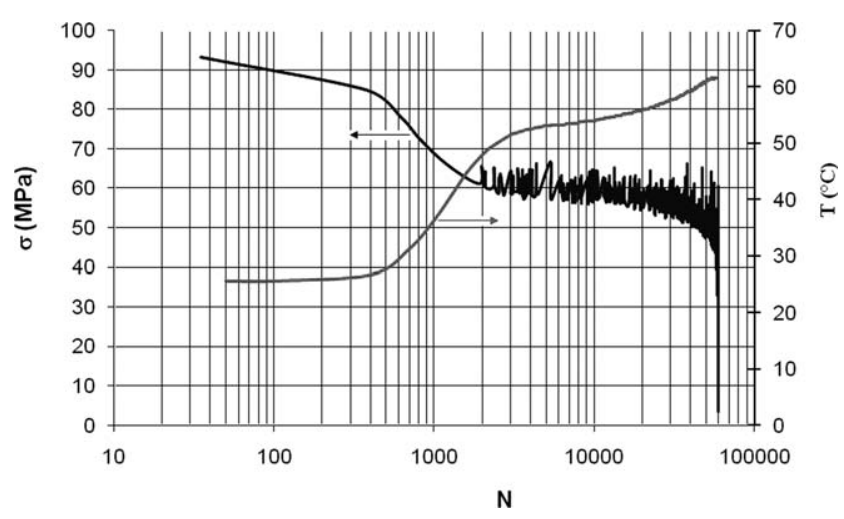

Figure 4 Induced stress and temperature versus number of cycles of a fatigue test at $10 \mathrm{~Hz}$ and $\varepsilon=0.017$. standard deviation. The standard deviation values are high for 500,000 loading cycle samples and reflect the heterogeneity of these samples, heterogeneity, which is also noticed for density and cristallinity ratio measurements.

Polysequential fatigue tests are carried out at $10 \mathrm{~Hz}$ frequency and an applied amplitude strain $\varepsilon=0.017$. Figure 4 displays the induced amplitude stress and the temperature versus the number of cycles. The curve $\sigma=f(N)$ displays after 2000 cycles a very noisy pattern due to electronics noise. A first decrease of the induced stress from 85 to $60 \mathrm{MPa}$ is observed between 500 and 3000 cycles. It goes with an increasing temperature from 27 to $53^{\circ} \mathrm{C}$, and then the temperature keeps on increasing but more slowly. This temperature increase induced by self-heating is smaller than the one reported before for another PA66/glass fiber composite material. ${ }^{1}$ The main difference between both composites is the sizing of glass fibers, which is specific to PA66, whereas in the previous study, the sizing of glass fibers is unknown and probably much less efficient. The low-mechanical resistance of the interface favors crack initiation and, as a consequence, an excess of self-heating temperature rise. This behavior can be explained with the viscoelastic spectrum (Fig. 5), performed at the same frequency, $10 \mathrm{~Hz}$. Figure 5 displays the variation of the storage modulus $E^{\prime}$, the loss modulus $E^{\prime \prime}$, and the damping $\tan \delta$ equal to the ratio $E^{\prime \prime} / E^{\prime}$. The increasing temperature from 27 to $53^{\circ} \mathrm{C}$ is due to an increasing value of the loss modulus $E^{\prime \prime}$. The dissipated heat at each mechanical cycle is proportional to the angular frequency $\omega$, the applied amplitude strain $\varepsilon_{0}$, and the loss modulus $E^{\prime \prime}$.

$$
Q \propto-\frac{1}{2} \omega \varepsilon_{0}^{2} E^{\prime \prime}
$$

These successive breaks do increase the fatigue lifetime $(65,000$ cycles instead of 60,000 cycles at break). Optical microscopy observations are carried out on the most constrained part, which has been polished before the test. Sample polishing can have opposite effects on the fatigue life. On one hand, it

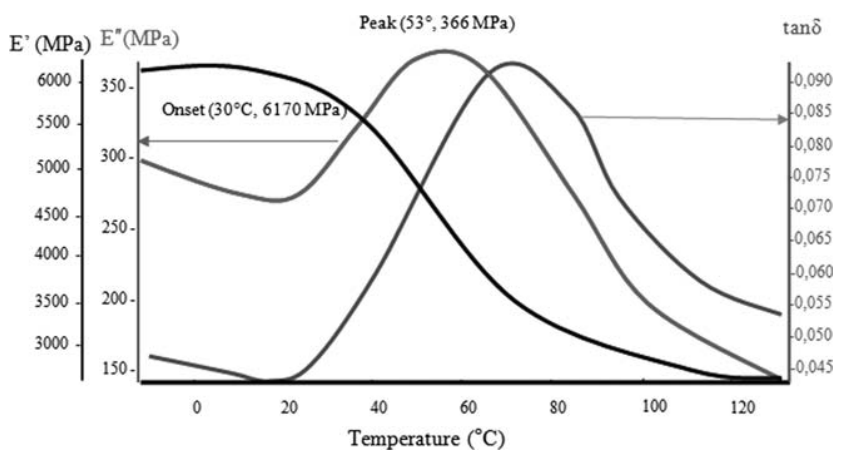

Figure 5 Viscoelastic spectrum of PA66/glass fiber at 10 $\mathrm{Hz}$ between -10 and $130^{\circ} \mathrm{C}$. 

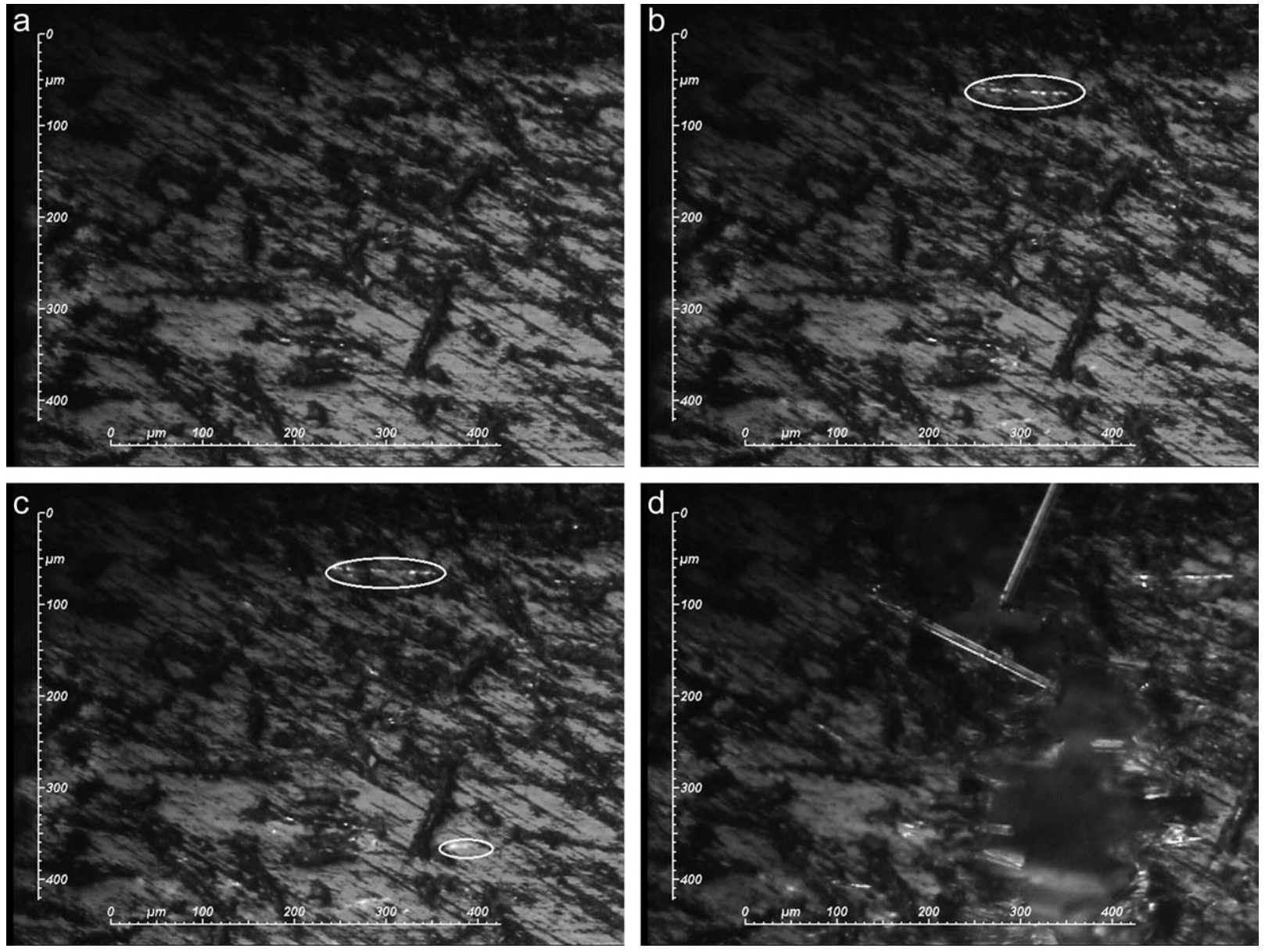

Figure 6 Optical microscopy observation of the most constrained part of a specimen tested at $10 \mathrm{~Hz}$ and $\varepsilon=0.017$ (polysequential test) (a) initial, (b) 30,000 cycles, $T=57^{\circ} \mathrm{C}$, (c) 45,000 cycles, $T=60^{\circ} \mathrm{C}$, (d) 60,000 cycles, $T=62^{\circ} \mathrm{C}$.

can suppress surface microdefects induced by internal stresses, which are built-up during processing cooling and which possibly initiate microcracks and thus increase the fatigue life. On the other hand, it can modify the sample geometry, and this possibly will decrease the fatigue life. For instance, in adhesively bonded structures, the removal of the adhesive fillet has been found to reduce fatigue life. ${ }^{7}$ By optical microscopy, no damage is observed before 30,000 cycles [Fig. 6(a)]. From this number of cycles, some pull-out fibers appear near the surface but only in the most constrained part [Fig. $6(\mathrm{~b}, \mathrm{c})]$, and microvoids/cracks are only visible just before the break Figure 6(d).

Then the study is carried on with an unpolished sample by using scanning electron microscopy [Fig. 7(a)]. Another kind of damage is observed: after 1000 cycles, some fiber ends (surrounded by a white circle on the figure) are pulling out near the surface and initiate the skin fracture [Fig. $7(\mathrm{~b}, \mathrm{c})]$. This damage is nanoscale size that is why we call it nanodefects. Microcracks, $\sim 5 \mu \mathrm{m}$, are observed just before failure [Fig. 7(d)]. It is very difficult to stop the fatigue test just before the sample failure, because the last phase of crack propagation is very fast. Cracks propagate first in zones where the fiber concentration is high [Fig. 8(a)] and then in the matrix until the final fracture [Fig. 8(b)]. This scenario recalls the work about the essential work of fracture of polyamide 66 filled with $\mathrm{TiO}_{2}$ nanoparticles. ${ }^{8}$ Individual nanoparticles act as stress concentration points, which promote tiny cavitations that coalesce into submicron ones, then rapidly grow into microvoids, and initiate cracks due to the high-level stress concentration.

For the test conditions used for polysequential fatigue tests, the number of cycles at fracture, $N_{r}$, is 65,000 . The fatigue lifetime increases with the rest time and is the highest when the break occurs close to the final fracture (Fig. 9), where the crack size is in a micron scale \{see, for instance [Fig. 7(d)]\}. It means that relaxation of defect build-up at the end of the damage initiation period is more efficient than the relaxation of defects build-up earlier. The points on vertical axis represent fatigue tests, which have been carried on until failure. The fatigue life is 

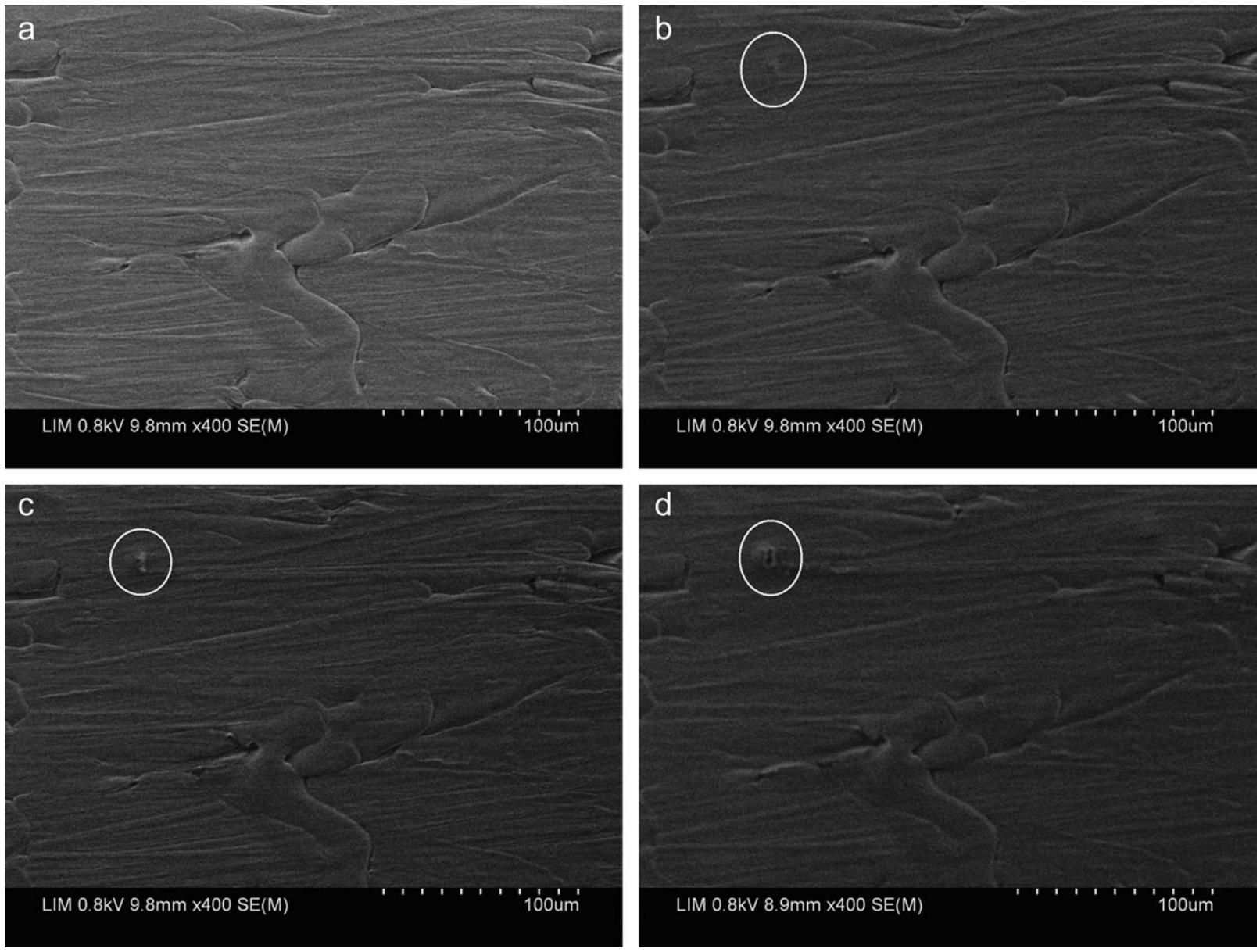

Figure 7 SEM observation of the most constrained and polished area of a specimen tested at $10 \mathrm{~Hz}$ and $\varepsilon=0.017$ (polysequential test) (a): initial, (b) 1000 cycles, $T=35^{\circ} \mathrm{C}$, (c) 5,000 cycles, $\mathrm{T}=52^{\circ} \mathrm{C}$, (d) 10,000 cycles, $\mathrm{T}=55^{\circ} \mathrm{C}$. The white circles indicate the fiber ends that are pulled out.

shorter than for polysequential tests carried out in the same test conditions. The effect of the rest time can be explained in terms of defects relaxation or in terms of increasing strength of the specimen induced by the temperature decrease. The shape of the temperature curve during the test, Figure 10 indicates that the temperature decrease is quite fast. At the beginning of the rest time, the temperature is equal to $62^{\circ} \mathrm{C}$, then it decreases quickly, in $7.5 \mathrm{~min}$ until $25^{\circ} \mathrm{C}$, and then much more slowly $(11.5 \mathrm{~min})$ to $22^{\circ} \mathrm{C}$. However, the most efficient rest time is $20 \mathrm{~min}$, which favors the explanation of increasing life time in terms of defect relaxation even if a temperature effect cannot be kept out. Figure 11 shows that an increasing rest time up to $20 \mathrm{~min}$ does increase the fatigue lifetime. Afterward, between $20 \mathrm{~min}$ and $2 \mathrm{~h}$, the number of cycles at fracture remains constant, about equal to 110,000 cycles. That means that for an applied amplitude strain, $\varepsilon_{0}=$ 0.017 , a rest time of $20 \mathrm{~min}$ is enough for microdefects relaxation. When a rest time of $5 \mathrm{~min}$ is applied close to the final fracture, the mean stress induced is equal to $63 \mathrm{MPa}$, hence a $21 \mathrm{MPa}$ gap with the initial and maximum induced stress. If the rest time is equal to $20 \mathrm{~min}$, the mean amplitude of the induced stress $(82 \mathrm{MPa})$ is practically equal to the initial and maximum amplitude of the induced stress (84 MPa). Now, the question is: what is the nature of the microdefects relaxed during the fatigue test break? Are they conformational changes in the amorphous phase? Robertson ${ }^{9}$ considered for polystyrene and polymethyl methacrylate, a molecular model in which a shear stress field induced rotational conformations of backbone bonds, enough numerous to induce an increasing concentration of flex bonds, which are in a rotational conformation different from the initial one (Fig. 12). These changes in rotational conformations induce an increasing disorder and increasing volume, a polymer structural state similar to the rubbery state observed at $T>T_{g}$. As a consequence, these changes break up the rigidity and allow plastic flow. An empirical equation binding the induced maximum strain rate to the test temperature and to the applied shear stress is used 

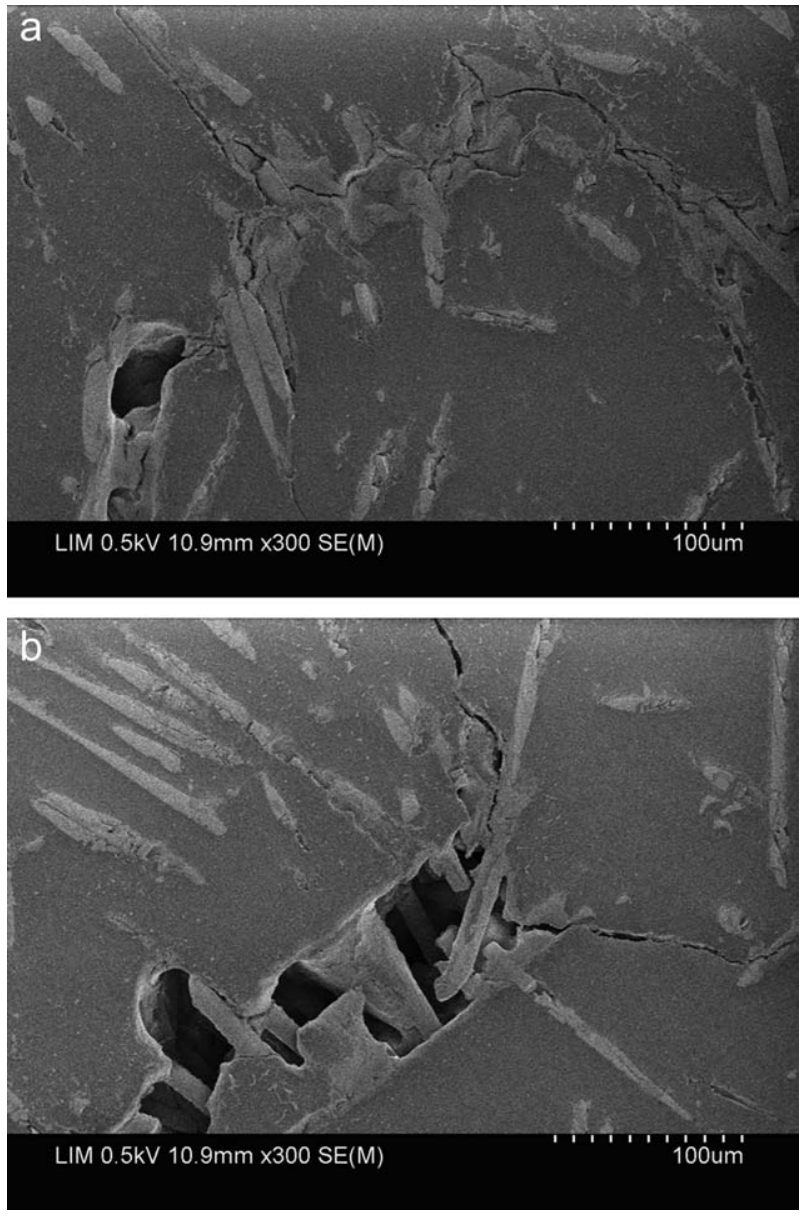

Figure 8 SEM observation of the most constrained and unpolished area of a specimen tested at $10 \mathrm{~Hz}$, just before fracture $(62,000$ cycles). (a) Crack propagation in zones with a high fibers concentration and (b) crack propagation in the matrix.

to calculate the plastic strain properties of the polystyrene and polymethyl methacrylate. The results are then confronted with experimental results of cold drawing experiments, and their good agreement validates the model. Could they be packing density defects, for instance, at the interphase crystalline/amorphous phases? An amorphous polymer

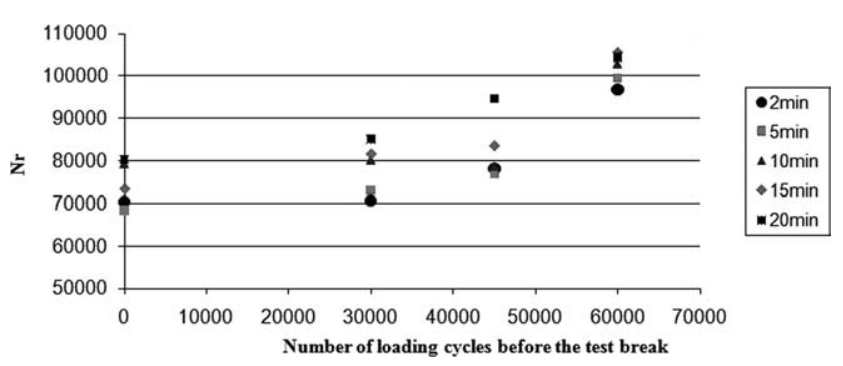

Figure 9 Variation of the cycle number at fracture $\left(N_{r}\right)$ versus the number of loading cycles $(N)$ before the test break and for various rest times. $\varepsilon_{0}=0.017, \sigma \sim 90 \mathrm{MPa}$, $\omega=10 \mathrm{~Hz}$, and $\% \mathrm{RH}=50$.

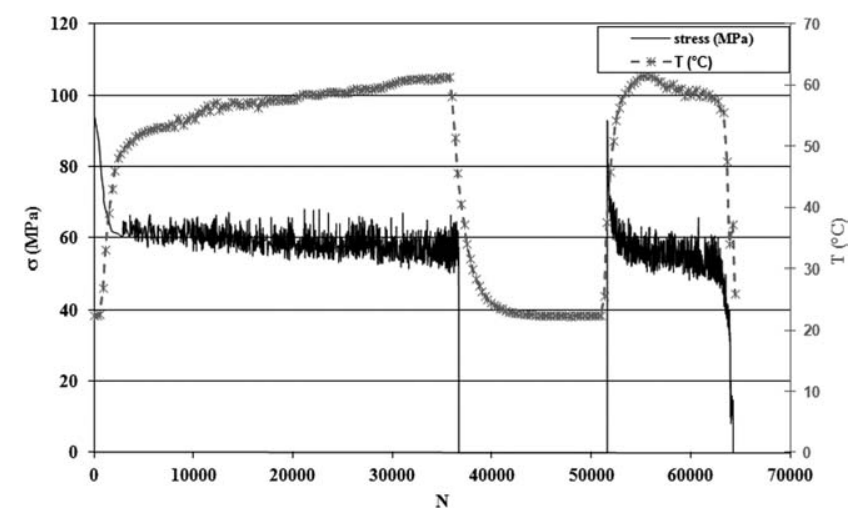

Figure 10 Induced stress and temperature variation during a polysequential test at $10 \mathrm{~Hz}, \varepsilon_{0}=0.016$ with a rest time of $25 \mathrm{~min}$ near the fracture.

can stand for a disorganized arrangement of structural units, ${ }^{10}$ each unit being located in a cage built up by the neighbor structural units. A "quasi-punctual defect" is a spot made up by a structural unit and her first neighbors (the cage cited above) of which the free enthalpy level is higher than the mean value of the whole group of structural units. These "quasi-punctual defects" correspond to local density fluctuations existing in the liquid state and which are frozen in the glassy state. They are in a physical nonequilibrium state and thermoreversible. $^{10}$ The reversible character of these defects implies that polysequential tests should be done to study the effect of a rest time (relaxation time) on the fatigue behavior. A decreasing concentration of these punctual defects does increase the fatigue lifetime. Fatigue craze initiation was investigated in polycarbonate. ${ }^{11}$ The disentanglement of polymer chains plays an important role in void-like structures or "protocrazes" with a size of $\sim 50 \mathrm{~nm}$. Could the same phenomenon occur in the amorphous phase of polyamide 66? Are these defects preplasticized domains again in the matrix? The preyield and yield behavior of amorphous polymers have been

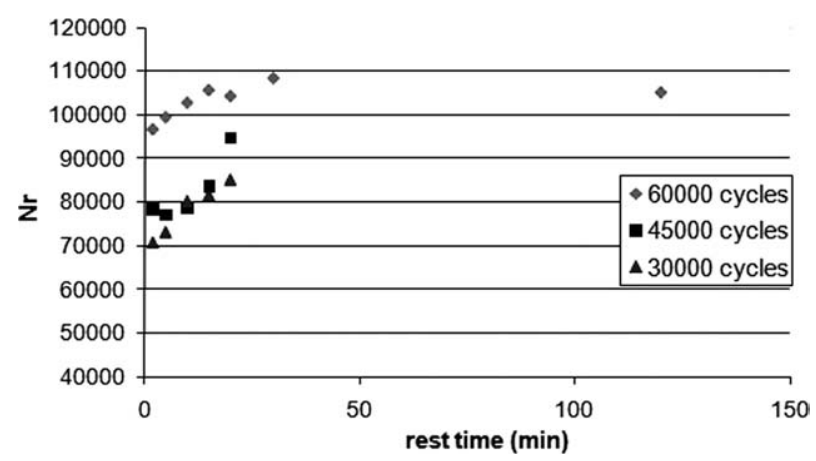

Figure 11 Variation of the cycle number at fracture, $N_{r}$, versus the rest time for three values of the number of loading cycles before the test break. $\varepsilon_{0}=0.017, \sigma \sim 90 \mathrm{MPa}$, $\omega=10 \mathrm{~Hz}$, and $\% \mathrm{RH}=50$. 


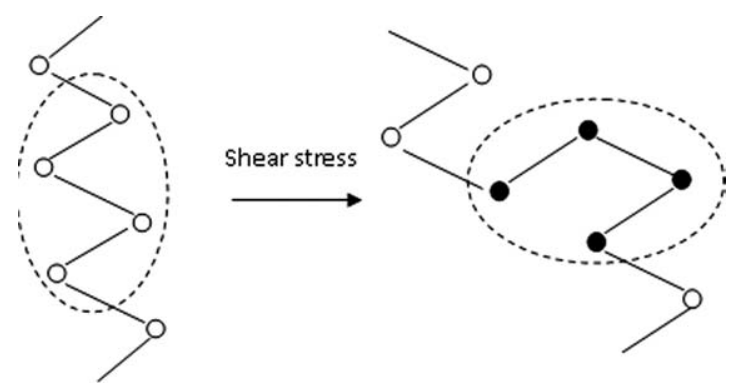

Figure 12 Change in rotational conformation $\bigcirc$ trans conformation (low energy state), - cis conformation (flexed state).

described with a metallurgical approach. ${ }^{12}$ Some new mechanical data were analyzed in terms of dislocation-like defects involved by deformation in the macromolecular chain arrangement. The comparison of the fatigue behavior of the composite and its neat matrix gives interesting information. Figure 13 shows the evolution of the induced amplitude stress versus the number of loading cycles for the composite and the neat matrix strained at $10 \mathrm{~Hz}$ frequency with an applied amplitude strain $\varepsilon_{0}=0.019$. The induced stress is three times higher for the composite than for the neat matrix, and, of course, the fatigue lifetime is much shorter. The first reason is the difference in elastic modulus value, but the second one is the difference in self-heating. The surface temperature in the most constrained part of the specimen is recorded during the test (Fig. 14). The temperature rise of the composite is higher than the one of the neat matrix. Nanocrack build-up at fiber ends, precursors of microcracks, induces an increasing damping and thus a higher temperature increase. The gap between the number of cycles corresponding to these two rises of temperature means that the crack build-up at fiber ends plays a key role in damage initiation. Are these defects relaxed during

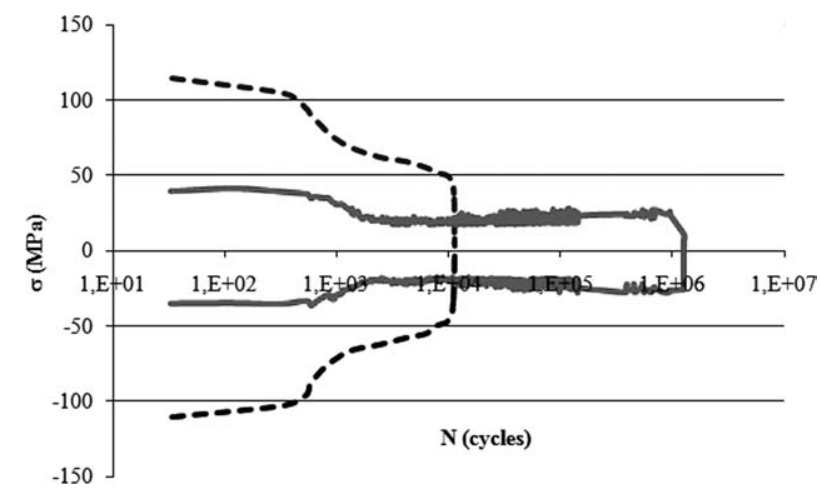

Figure 13 Induced stress of the neat matrix (dashed line) and of the composite (dotted line) versus the number of loading cycles, tested at a $10 \mathrm{~Hz}$ frequency, $\varepsilon_{0}=0.019$, and $\% \mathrm{RH}=50$.

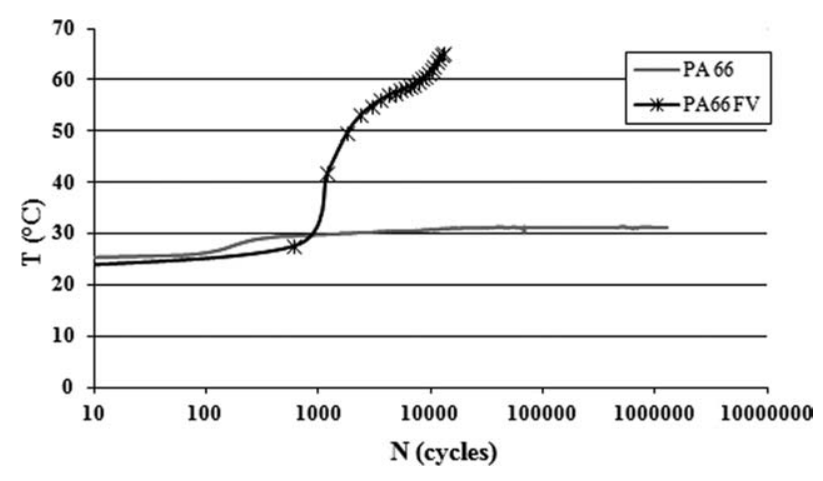

Figure 14 Surface temperature of the neat matrix (dashed line) and of the composite (dotted line) versus the number of loading cycles, tested at a $10 \mathrm{~Hz}$ frequency, $\varepsilon_{0}$ $=0.019$, and $\% \mathrm{RH}=50$.

the test break off, identical to the microcracks that coalesce in zones where the fiber concentration is high? It is reasonable to answer positively, because at the end of a rest time of 20 min just before the final fracture, the induced stress when the strain is again applied is equal to the maximum and initial induced stress. Before the test interruption, the temperature involves a decreasing value of the elastic modulus. As the applied strain is constant, the induced stress decreases that favors an increasing life time. At the beginning of the rest time, the temperature decreases (Fig. 10) and, as a consequence, the elastic modulus and the induced stress increase again, which would decrease the fatigue lifetime. The opposite effect is noticed, so that the temperature variation during the rest time does not involve an increasing fatigue lifetime. But, at the beginning of the rest time, the temperature is higher than the glass transition temperature. Thus, the matrix is in a rubbery state and its molecular mobility is high enough to induce the closing/deletion of microcracks. So, it is reasonable to assume that relaxation of macromolecular chains in the region of microdefects is well responsible for the increasing number of cycles at break.

\section{CONCLUSIONS}

A fatigue curve displays three zones, of which the second one is very long, nearly $80 \%$ of the fatigue life, when the applied strain is low; during this period, damage initiation occurs, but the size/ concentration of microdefects build-up is too small to involve a change in macroscopic properties such as density, cristallinity, and flexural elastic modulus. At the beginning of the third zone, which is short compared to the second one, cracks propagation first occur in zones where the fiber concentration is high, then in the matrix until the final fracture. The fatigue lifetime is higher during polysequential tests 
than during nonstop tests. The most efficient break is just before fracture. There is an optimum rest time for microdefects relaxation, which is equal to $20 \mathrm{~min}$ for our material and testing conditions. The nature of these relaxed microdefects was investigated by comparing the fatigue behavior of the neat matrix and of the composite. For identical testing conditions, the self-heating of the composite is higher than the one of the neat matrix. It means that nanocracks build-up at fiber ends, and precursors of microcracks play the key role. The comparison of the initial induced stress and the induced stress after a rest time just before the specimen fracture seems to indicate that these microcracks are closed during the rest period.

Many thanks to Gilles Robert for helpful discussion and Rhodia Co for providing PA66/glass fiber compounds.

\section{References}

1. Bellenger, V.; Tcharkhtchi, A.; Castaing, Ph. Int J Fatigue 2006, 28, 1348.

2. Noda, K. Polymer 2001, 42, 5803.

3. Horst, J. J.; Spoomaker, J. L. J Mater Sci 1997, 32, 3641.

4. Baltenneck, F.; Trotignon, J.-P.; Verdu, J. Polym Eng Sci 1997, 37, 1740 .

5. Mark, J. E. Polymer Data Handbook; Oxford University Press: New York, 1999; p 195.

6. Barbouchi S., Bellenger V., Tcharkhtchi A., Castaing Ph, Jollivet $\mathrm{T}$. Effect of water on the fatigue behavior of a PA66/glass fibers composite material. J Mater Sci 2007, 42, 2181.

7. Crocombe, A. D.; Ong, C. I.; Chan, C. M.; Wahab, M. M. A.; Ashcroft, I. A. J Adhes 2002, 78, 745.

8. Yang, J.; Zhang, Z.; Zhang, H. Comp Sci Technol 2005, 65, 2374.

9. Robertson, R. E. J Chem Phys 1966, 44, 3950.

10. Perez, J. Physique et Mécanique des Polymères Amorphes. Technique et Documentation Lavoisier: Paris; 1992; p 34-35.

11. Hristov, H. A.; Yee, A. F.; Gidley, D. W. Polymer 1994, 35, 3604.

12. Escaig, B. Polym Eng Sci 1984, 24, 737. 